\title{
An Empirical Approach to Aesthetic Adjectives
}

\author{
Isidora Stojanovic \\ Institut Jean-Nicod, Département d'Études Cognitives, École Normale \\ Supérieure, Centre National de Recherche Scientifique, PSL Research \\ University, France \\ isidora.stojanovic@ens.fr \\ final draft for Florian Cova \& Sébastien Réhault (Eds.) \\ Advances in Experimental Philosophy of Aesthetics, Bloomsbury
}

\begin{abstract}
This chapter surveys some recent studies of aesthetic adjectives in theoretical and experimental linguistics, evaluates the impact of these studies on our conceptual understanding of aesthetic discourse, and discusses the prospects for future investigations. After providing some background on the semantics of adjectives, I present the experiments from Liao and Meskin (2017), which suggest that the aesthetic adjectives 'beautiful', 'ugly' and 'elegant' do not fit squarely into the standard typology of adjectives. I discuss various semantic and pragmatic factors that may be responsible for the observed results, and close with some thoughts about what the next steps of inquiry should be.
\end{abstract}

Keywords: Aesthetic adjectives; gradable, relative and absolute adjectives; context-sensitivity; the semantics-pragmatics interface.

\section{Introduction}

We all have a certain intuitive grasp on the difference between evaluative aesthetic statements and non-aesthetic statements. Consider the following statements about the Korean movie The Wailing (Goksung):

1. This is another superb film from Na Hong-jin. (Jonathan Hathfull, SciFiNow, 20 July 2016). ${ }^{1}$

2. Terrible. Overly-long, awfully executed film. (Sam Kearny, Rotten

\footnotetext{
${ }^{1}$ Extracted from larger text: "With beautiful, epic cinematography of the mountain forests from Hong Kyung-pyo, some very effective sudden shocks, and a powerful blend of detective story, occult horror and Stephen King-esque small-town suspicion, this is another superb film from Na Hong-jin." Full review available here: https://www.scifinow.co.uk/reviews/the-wailing-film-review-fantasia-2016/
} 
Tomatoes Audience Reviews, 19 November 2016). ${ }^{2}$

3. The movie opens with a police sergeant, Jong-gu, investigating a double murder in his quiet, rural village. (Glenn Kenny, New York Times, 2 June 2016). ${ }^{3}$

The first two statements express aesthetic evaluations of the movie at stake - positive, in the case of (1), negative in the case of (2)) - and in this respect, stand in clear contrast with (3), which is a merely descriptive statement about the movie.

While the contrast between (1) and (2), on the one hand, and (3), on the other, seems clear and uncontroversial, there are many statements that broadly belong to aesthetic discourse, yet which we are more reluctant to classify outright as aesthetic statements. Consider:

4. Two-and-a-half hours long, but never slow, the Wailing takes its time to burrow under your skin, but by the time it weaves its dark, potent spell, it leaves you with a lingering, unshakeable sense of dread that Hollywood horror films can rarely muster. (David Hughes, Empire, 21 November 2016). ${ }^{4}$

(4) shares features with descriptive statements such as (3) as well as with evaluative statements such as (1) or (2). Like (3), it describes the movie, but unlike (3), the aim of the description is not, or at least not only, to inform the interlocutor about what the movie is like. Rather, the aim of (4) is to describe the movie in such terms as to enable the speaker to convey his overall assessment of the movie. In this case, the speaker conveys a positive evaluation; however, unlike (1) or (2), the way in which the evaluation is conveyed relies on a large array of factors, including general knowledge about cinema, a set of shared (aesthetic and other) values, expectations about the intended interpretation and similar pragmatic factors.

Although (4) may be more representative of aesthetic discourse than (1) or (2), current research in the semantics of aesthetic expressions tends to focus on statements like "the movie is superb" or "the movie is terrible", and I shall align here with this tendency. The chapter is structured as follows. Section 2 provides some background on the classification of adjectives. Section 3 presents the experimental studies from Liao and Meskin (2017), which aim to show that aesthetic adjectives pose a challenge for this classification. Section 4 discusses three sets of factors that may be responsible, at least in part, for the observed results, and concludes with some thoughts about possible future investigations.

\footnotetext{
${ }^{2}$ Extracted from larger text: "Terrible. Impossible to empathize with such a useless protagonist. Overlylong, awfully executed film." https://www.rottentomatoes.com $/ \mathrm{m} /$ the_wailing/reviews/?type=user

3 http://www.nytimes.com/2016/06/03/movies/the-wailing-na-hong-jin-review.html

${ }^{4}$ http://www.empireonline.com/movies/wailing/review/
} 
Adjectives have been studied in formal semantics for several decades; a taxonomy has been established that helps to classify them in virtue of their semantic features. One of those features is gradability. Intuitively, gradable adjectives are those that ascribe properties that an object can have to a certain degree, while non-gradable adjectives ascribe properties that cannot be graded, but that an object either has or lacks. To continue in the realm of movie talk, consider the (compound) adjective ' 15 rated'. Any movie either is or is not 15 rated (that is, is restricted to audiences of 15 years or over), and it makes no sense to ask how much a movie is 15 rated, or whether one movie is more 15 rated than another. By contrast, the adjective 'long' describes a property that movies can have to a greater or a lesser degree. A movie that is long can be very long or can only be a bit long, and some movies are longer than others. An easy way to check whether an adjective is gradable is to check whether it is felicitous in comparative constructions.

Gradability is probably the feature of adjectives that has been most discussed in the semantic literature on adjectives (see Kamp (1975) or Klein (1980) for early works, Heim (2000), Rotstein and Winter (2004), or McNally and Kennedy (2005) for classic works, and Morzycki (2015) or Burnett (2016) for more recent works). Gradability is a very common feature, among aesthetic adjectives and in general. 'Beautiful', 'ugly' and 'pretty' are clearly gradable, and so are arguably all the adjectives that figure in the list given in Sibley (1959: 421) as core examples of aesthetic concepts: unified, balanced, integrated, lifeless, serene, somber, dynamic, powerful, vivid, moving, trite, sentimental, tragic, graceful, delicate, dainty, handsome, comely, elegant, garish, dumpy.

Let us momentarily bracket the issue of how best to account for gradability, and turn to a further division among gradable adjectives. Consider these two pairs of antonyms: 'long' vs. 'short', on the one hand, and 'full' vs. 'empty', on the other. All four adjectives are gradable: just as things can be longer or shorter, they can be fuller or emptier. Consider a theatre that is occupied to two thirds of its capacity on Friday night, and to only one third on Saturday night. Then we would naturally say that the theatre was fuller on Friday night than on Saturday, and conversely, that on Saturday night it was emptier than on Friday, although on neither occasions it was either full or empty. For a theatre to be full, it should be occupied to the maximum of its capacity, and for it to be empty, there should be not a single person in it. ${ }^{5}$ Now, 'short' and 'long' are different in that respect. Consider two roads, respectively $200 \mathrm{~km}$ and $20 \mathrm{~km}$ long. This still does not give us enough information in order to decide whether those roads are long or short. Thus in a situation in which the only way to get from one place to the other is on foot, even the $20 \mathrm{~km}$ road will likely count as long. Conversely,

\footnotetext{
5 Of course, we may, and do, describe a theatre as "empty" when there are only very few people in it, but even then, we would not say that it was empty strictly speaking. I must postpone the discussion of such uses to section 4.1 .
} 
in a situation in which we discuss, say, the China network of bullet trains, even the $200 \mathrm{~km}$ road will likely count as short. The upshot of these examples is that in order to decide whether something is long or short, it is typically not enough to know how long it measures. What is further required is that the context should supply some reference - a threshold, a comparison class, or a standard - relative to which we assess the length of the thing at stake. ${ }^{6}$

To bring the point home, relative gradable adjectives are those that, like 'long', 'short', 'cheap', 'expensive', 'cold' or 'warm', do not already come with a standard, so to speak, but require the context to provide one. In contrast, absolute gradable adjectives, such as 'empty', 'full', 'open', 'closed', 'bent' or 'straight', are such that their standard is given in advance. Thus for a thing (such as a door) to be open is for it to have some degree of aperture, and to be closed is to have zero aperture; for a thing to be straight is to have zero deviation, and to be bent is to have some degree of deviation; and so on. While this is an intuitive approximation to the relative-absolute distinction, there are linguistic tests that motivate it more robustly. The tests fall into two categories, the first having to do with the way in which these adjectives combine with various modifiers, the second having to do with the entailments that are triggered by the use of these adjectives in a comparative form. Let us look more closely at each.

There is a fair amount of agreement among scholars that the modifier 'very' is felicitous with relative adjectives, but not so with absolute adjectives. Compare:
8. This road is very long.
9. The rent was very expensive.
10. \#The room is very empty.
11. \#The door was very closed.

Conversely, there are modifiers, such as 'completely' and 'almost', that are felicitous when used with an absolute adjective, but not so with a relative one. Compare:

12. \#This road is completely long.

13. ??The rent was almost expensive.

14. The room is completely empty.

15. The door was almost closed.

As it often happens with felicity judgments, tests of this sort may not always provide a clear-cut division. Take, for instance, the adjective 'dark', which appears to work fine with all three modifiers:

18. The room was very dark.

19. The room was completely dark.

20. The room was almost dark.

\footnotetext{
${ }^{6}$ How the context does that is a tricky issue, discussed in the debates on vagueness (Fara 2000) and on metasemantics (Glanzberg 2007). The issue largely depends on how one approaches the interface between semantics and pragmatics; something to which we will return when we get to discuss aesthetic adjectives.
} 
However, the fact that we may find adjectives that are felicitous with both kinds of modifiers (those, like 'very', which are typically felicitous with relative adjectives, and those, like 'completely' and 'almost', which are typically felicitous with absolute adjectives) is not by itself sufficient to discredit the relative-absolute distinction, for there can be both semantic and pragmatic explanations for a use that one would not initially expect - a point to which I will return in section 4.1 .

Let us now look at the second set of tests that aim to track the relative-absolute distinction. In the case of absolute adjectives, when the adjective is used to compare two things, that normally licenses some inference as to whether the adjective applies to those things or not. Adjectives that pattern like 'closed' or 'full' (whose standard lies at the upper endpoint of a scale, to use a semantic jargon) give us the entailment pattern in (21), as witnessed by the natural inference from (22) to (23):

21. A is more $\mathrm{F}$ than $\mathrm{B} . \mid-\mathrm{B}$ is not $\mathrm{F}$.

22. The room upstairs is fuller than the one downstairs.

23. The room downstairs is not full.

Other absolute adjectives, namely those that pattern like 'open' or 'bent' (and whose standard lies at the lower endpoint of a scale), give us the entailment pattern (24), as exemplified by the inference from (25) to (26):

24. $\mathrm{A}$ is more $\mathrm{F}$ than $\mathrm{B} . \mathrm{-}-\mathrm{A}$ is $\mathrm{F}$.

25. This rod is more bent than that one.

26. This rod is bent.

When it comes to relative adjectives, no such entailment patters are available.

\section{How do aesthetic adjectives fare with respect to the relative- absolute distinction?}

In a pioneering set of studies, Liao \& Meskin (2017) set out to examine how the aesthetic adjectives 'beautiful', 'ugly' and 'elegant' fit into the relative-absolute taxonomy. At first glance, 'beautiful' and 'ugly' pattern like relative adjectives: they are perfectly felicitous when combined with the modifier 'very', and sound marked, if not outright infelicitous, when combined with modifiers 'completely' or 'almost'?

27. The photography in The Wailing is very beautiful.

\footnotetext{
${ }^{7}$ In section 4, I will discuss the reliability of such felicity tests. For the time being, let me point out that both 'almost beautiful' and 'completely beautiful' do appear in corpora. Here is an example for the latter: "The sea can be frightening and threatening, or completely beautiful" (Tamara Moan, Capturing the Ocean in Pastel, American Artist 71 (2007): 54; source: COCA).
} 
28. ?? The photography in The Wailing is completely beautiful.

29. ?? The photography in The Wailing is almost beautiful.

'Beautiful', 'ugly' and 'elegant' also seem to pattern like relative adjectives when it comes to entailment tests. Consider two objects, say buildings, such that you would not describe them as "beautiful" (though they needn't be ugly either). It will still make sense to compare them as to which one is "more beautiful", as in:

30. The Ryugyong Hotel in Pyonyang is more beautiful than the Elephant Building in Bangkok (even though neither of them is beautiful).

Although initial evidence suggests that 'beautiful' is a relative gradable adjective, Liao and Meskin (2017) seek to establish that 'beautiful', 'ugly' and 'elegant' also differ significantly from paradigmatic relative adjectives, such as 'tall' or 'expensive', but at the same time also differ from the paradigmatic absolute gradable adjectives, such as 'full' or 'bent'. They write: 'Our results present a prima facie empirical challenge to a common distinction between relative and absolute gradable adjectives because aesthetic adjectives are found to behave differently from both." (2017: 371).

Liao and Meskin's motivation for this claim relies on a series of experiments designed to see how ordinary speakers understand those adjectives. For their experiments, they took inspiration in those conducted by Kristen Syrett (Syrett 2007, and Syrett et al. 2010), who sought to show that the relative-absolute distinction was not just a theoretical distinction, but also had a psychological reality. Syrett and her colleagues presented the participants (both children and adults) with pairs of object that are comparable in terms of a given property - such as length, openness, fullness, etc. - and asked them to choose the object with that property. For example, they would present them with two lines of different lengths and would instruct them to pick out "the long one." Or they would present them with two lines that are bent to different degrees and would ask them to pick out "the straight one." The crucial observation that Syrett et al. (2010) established with their experiments is that there is a striking difference between relative and absolute adjectives when it comes to answering this sort of task. For relative adjectives, speakers will naturally choose as "the F" that object which has F to a higher degree: e.g., they will pick out as "the long line" that line which is longer than the other. In the case of absolute adjectives, on the other hand, speakers are not disposed to understand "the F" as referring to the object that is more F than the other: e.g., if neither of the lines is straight, even though one is straighter than the other, they will not pick the straighter line as "the straight one"; rather, they will refuse to make any selection.

Liao and Meskin conducted four experiments, in which they applied Syrett's experimental paradigm to the aesthetic adjectives 'beautiful', 'ugly' and 'elegant'. In Study 1, they presented the participants with the following stimuli: disks that are spotted to different degrees, rods that are bent to different degrees, blocks that are long to different degrees, and faces that are beautiful to different degrees. The disks, 
rods and blocks stimuli were taken from Syrett (2007), while the faces stimuli consisted of photographs of one and the same face, digitally manipulated so as to exhibit three degrees of asymmetry. There were two comparison sets created, the first consisting of the least asymmetric and the intermediately asymmetric face, and the second consisting of the intermediately asymmetric and the most asymmetric face. ${ }^{8}$ The participants were then asked to select one response among the following:

31. Object A is the straight/spotted/ beautiful/ long object.

32. Object $\mathrm{B}$ is the straight/ spotted/ beautiful/ long object.

33. I can't. Neither object A nor object B is straight/ spotted/ beautiful/ long.

34. I can't. Both object A and object B are straight/spotted/ beautiful/ long.

Study 2 used again the "long" and "spotted" stimuli, but instead of 'beautiful' used its antonym 'ugly', and in addition to the face stimuli, there were two more sets of stimuli: pictures of one and the same car, digitally manipulated so that it looks brand new on the one, and old and decayed on the other, and pictures of one and the same flower, such that it looks all fresh on the one and all faded on the other. In Study 2, in addition to the multiple choice question as in (31)-(34), the participants were given a comparison task, and were asked to choose among "Object $\mathrm{A} / \mathrm{B}$ is uglier/longer/more spotted than object B/A", "Neither object is ugly/long/spotted" and "Both objects are equally ugly/long/spotted".

Before we move to the next two studies, let us pause to reveal the results of the first two. In Study 1, 97.4\% of participants complied with the request to pick out the long object, $17.9 \%$, with the request to pick out the straight object, and $10.3 \%$ with the request to pick out the spotted object. This replicates the results observed by Syrett and her colleagues. On the other hand, $43.6 \%$ of participants complied with the request to pick out the beautiful object amongst two faces, suggesting that 'beautiful' does not behave like 'long', 'straight' or 'spotted'. In Study 2, as previously noted, the participants were also tested for the comparative judgments, which gave a finding interesting in itself, since $37.1 \%$ did not find one face uglier than the other, $12.8 \%$ did not find one car uglier than the other, and $23.1 \%$ did not find one flower uglier than the other. Those participants who were unwilling to make a comparative judgment were then filtered out from the final results, yielding results similar to those obtained in Study 1. In a nutshell, almost everyone will pick out the longer block as "the long one" and almost no one will pick out the disk that has more spots on it as "the spotted one", while roughly one participant out of two (among those willing to make the comparative judgment) will pick out the "uglier" face, car or flower as "the ugly one".

In the next two studies, Liao and Meskin aimed to address several concerns with which the first two studies had been met. One of the concerns was the choice of the stimuli. For one thing, they realized that using digital variants of the same original photograph was problematic. As they themselves write: "Perhaps some participants

\footnotetext{
${ }^{8}$ Full material and data for all studies reported in Liao and Meskin (2017) are deposited in the Open Science Framework repository and openly available for access at https://osf.io/6uztd/.
} 
refused to make selective or comparative judgments when they deemed two stimuli as too similar or indistinguishable. Or perhaps some participants refused to make selective or comparative judgments when they saw two stimuli as depicting one and the same object." (2017: 382) For another, they decided to replace stimuli containing mundane objects (people, artefacts, plants) with works of art. The new stimuli consisted of (photographs of) abstract sculptures by Barbara Hepworth, Henry Moore, Constantin Brancusi, and Isamu Noguchi. Another concern was the methodology, which initially consisted in asking participants to assent to statements of the form "Object $\mathrm{A} / \mathrm{B}$ is the [ADJECTIVE] object". In the new studies, participants were asked to select "the [ADJECTIVE] one" by clicking directly on the relevant picture (and were also given the option of clicking on the button "I can't perform this task", which would prompt a window in which they could say why they could not perform it). In both studies, the stimuli were the same: the photographs of abstract sculptures, the blocks and the disks, and the adjectives tested were 'beautiful', 'elegant', 'long' and 'spotted'. The difference between the two studies is that in Study 3, the comparative task consisted in asking the participants to "pick out the one that is more beautiful/ elegant/ spotted/ longer", while in Study 4, they were asked to rate the two objects individually, each on a sliding scale, from 0 ("not at all") to 100 ("extremely").

The results obtained in the second two studies appear to be in line with those obtained in the first two studies. In Study 3, approximately one participant in 5 was unwilling to judge that one of the sculptures was either more beautiful or more elegant than the other. Once these participants were filtered out, the remaining results showed, just as in the earlier studies, that (with respect to the stimuli at stake) 'beautiful' and 'elegant' pattern differently both from 'long' and from 'spotted'; and Study 4 yielded similar findings.

\section{What do the studies in Liao \& Meskin (2017) actually show?}

The research conducted by Liao and Meskin (2017) unquestionably constitutes a groundbreaking step in the research on aesthetic adjectives. Its importance is twofold. First, it is one of the few recent attempts to examine how aesthetic adjectives fit into the general classification of adjectives, and to tackle the question of which semantic characteristics aesthetic adjectives display. It must be noted that, with few exceptions such as McNally and Stojanovic (2017) or Liao, McNally and Meskin (2016), this question has been largely ignored, despite an extremely lively interest in expressions that exhibit subjectivity, but which has focused almost exclusively on predicates of personal taste (for literature overview, see Bylinina 2014). Second, the methodology that they adopt nicely reflects a recent yet growing tendency to use experimental methods for the purpose of linguistic discovery.

Despite its unquestionable merits, Liao and Meskin's work and, in particular, the claims that they draw from their findings, have several shortcomings (some of which 
they themselves note, but then discard all too quickly). One of the main shortcomings it that the results of their experiments do not provide the ground for deducing any interesting conclusions regarding aesthetic adjectives. Let me explain. What the results show is that 'beautiful', 'ugly' and 'elegant', as applied to the stimuli presented to the participants, do not align either with 'long' or with 'spotted'. However, the studies do not reveal any stable pattern in the way in which the participants interpreted 'beautiful'. Recall that for an adjective such as 'long', and a stimulus consisting of two blocks one of which is clearly longer than the other, a great majority of participants picked out the longer block as "the long one". Similarly, for an adjective such as 'spotted', and a stimulus consisting of two disks one of which contains more spots than the other, a great majority of participants refused to pick out the disk with more spots on it as "the spotted one". In both cases, a clear tendency emerges. But what about the findings with 'beautiful', 'ugly' and 'elegant', as applied to the stimuli chosen by Liao and Meskin? Roughly, half of the participants comply with the request, and another half don't. This looks very much like a pattern of choosing at chance: no stable behavior is observed across the participants' behavior. In a hypothetical experiment in which the participants were presented with a task for which they were clueless, we would expect similar findings: a random choice between two options which might seem equally plausible. In order to demonstrate that aesthetic adjectives behave differently both from relative and absolute adjectives, Liao and Meskin should have provided a study in which a great majority of participants replies in one way in the case of relative adjectives and in another way in the case of aesthetic adjectives, and a related study in which, again, a great majority replies in one way in the case of relative adjectives and in another way in the case of aesthetic adjectives. ${ }^{9}$

The studies in Liao and Meskin (2017), as I see them, are only a first step in what will hopefully become a steady and fruitful line of research. In the remainder of this section, I would like to discuss two ideas. The first is the idea that adjectives (like many other words) manifest shifts in meaning, and, in particular, that a relative adjective can, in a suitable context, behave like an absolute adjective, and vice versa. The second is the idea that that the participants of the studies at stake are unwilling to accommodate the presuppositions of existence and uniqueness for reasons that have little to do with aesthetic adjectives per se, but are due to the choice of stimuli and to the artificial nature of the tasks.

\subsection{Meaning shifts and the relative-absolute distinction}

My first concern is that it is unclear to which extent the puzzling data that Liao and

\footnotetext{
9 Another thing to note concerning the results, yet one to which Liao and Meskin do not seem to pay attention, is that the compliance rate for 'beautiful' found in Study 1 was significantly lower than the compliance rate in Studies 3 and 4 (viz. less than 50\% vs. almost 80\%). This gives further reason to think that the studies taken together do not reveal any stable pattern for the interpretation of 'beautiful'.
} 
Meskin (2017) have brought to light are due to features proper to aesthetic adjectives, and to which extent they are due to more general features of adjectival meaning. Let me explain. In section 2, I presented the distinction between non-gradable and gradable adjectives as a sharp and robust distinction, and similarly for the distinction between relative and absolute adjectives. However, it can easily happen that an adjective that belongs to one of the categories can acquire a usage that puts it into the other category. Consider the adjective 'pregnant', as applied to women or female animals. It means "having a child or young developing in the uterus" (The Oxford Dictionary), which is a yes-no property, that is, a property that an individual either has or lacks, and that does not come in degrees. This places the adjective on the nongradable side. Nevertheless, one can easily find occurrences in which the adjective is graded, as in:

35. By now, just about everyone has seen the cover of that magazine, Demi Moore - regal, nude and very pregnant, a startling icon in those photographs taken by Annie Leibovitz. (From "Breaking Pregnancy Taboos; ABC Primetime 1991; source: COCA)

Indeed, there are 108 occurrences of "very pregnant" in the Corpus of Contemporary American English, COCA; and in none of them is the adjective used with its other meaning, which is gradable and which The Oxford Dictionary paraphrases as "full of meaning; significant or suggestive" (as "a development pregnant with implications").

What happens in examples such as (35) is that the adjective's interpretation gets shifted to a property that comes in degrees, for instance, "exhibiting those features typical of someone who has a child or a young developing in the uterus". Such meaning shifts are available for a large number of non-gradable adjectives. Take 'human': its primary meaning is non-gradable, but it is often used in an extended meaning, paraphrased as "exhibiting the better qualities of the humankind" and which does allow for degree modification. Or take nationality adjectives, such as 'English' or 'Vietnamese'; non-gradable, they merely mean that the subject belongs to the relevant nationality; gradable, they mean that the subject exhibits properties typical of the relevant nationality - which, again, admits degrees. In fact, it may even be argued that the primary meaning of 'spotted', an adjective that figures in all four studies, is a non-gradable one, while the gradable meaning is a derived one.

Just as many adjectives may shift between gradable and non-gradable uses, it is plausible to think that many may shift between relative and absolute uses, perhaps with even greater ease. I stressed earlier that one of the criteria that indicates that a given adjective is not relative is the infelicity of modifying it with 'very'. Yet 'very closed' does have natural occurrences - over 50 found in COCA. To be sure, for most of them, the things described as "very closed" are societies, communities, or circuits, rather than doors, so one could think that the two adjectives, the absolute and the relative one, denote different properties. However, this shift in meaning (assuming that there is one) results from what makes a thing such as a society open (such that 
you can penetrate it) or closed (such that you cannot penetrate it), and it is that which is responsible for the felicity of combining the adjective with a degree modifier, rather than anything in the meaning of the adjective itself.

Just as 'closed', a paradigmatic absolute adjective, can shift to a relative one, we should expect that a relative adjective can shift to an absolute one - that is, becomes such that there is a minimum or maximum standard fixed for its application. Take 'dark', traditionally classified as a relative gradable adjective (e.g. Solt 2016). Yet there is hardly any awkwardness perceived in constructions such as 'almost dark' or 'completely dark', as witnessed by: ${ }^{10}$

36. When he stepped into the room it was almost dark (...) (Kent Haruf, Plainsong, New York: Vintage Books; source: COCA)

To bring the point home, it should not come as much of a surprise if the adjectives 'beautiful', 'ugly' and 'elegant' showed some shiftiness in their behavior. And indeed, Liao, McNally and Meskin argue that 'beautiful' and 'elegant' come out as relative on some tests and absolute on other tests. They argue, in particular, that both adjectives are felicitous with 'almost', by pointing out the following contrasts (2016: 627, their examples (13b), (14a) and (14b)):

37. \#The room is almost big.

38. The cemetery was almost beautiful.

39. The rooms were clean and almost elegant.

There is indeed a prima facie contrast between (37), on the one hand, and (38) or (39), on the other. However, I contend that the contrast is enhanced by the difference in tense (present tense in (37) vs. past tense in (38) and (39)) and, perhaps relatedly, because it is easier for the hearer to imagine a suitable context that makes (38) or (39) felicitous than it is for (37). For instance, a natural way of understanding (38) is as making reference to the appearance of the cemetery on a particular occasion, and reporting it as getting very close (hence the 'almost') to what can be described as a "beautiful" scenery. (39):

Conversely, consider the following use of 'almost big', minimally different from

\footnotetext{
10 Admittedly, it is easier to endow 'dark' with an absolute interpretation (that is, an interpretation such that there is a minimum and/or a maximum standard that licenses its use) than it is for other relative adjectives, such as 'big' and 'tall'. But even those occur naturally. Here are uses of 'almost big' and 'almost tall' found in fiction writing:

(1) "His name was Steve or something equally ordinary -- a fellow almost big, lean and strong in a haphazard youthful way." (Robert Reed, The Shape of Everything, 1994, Fantasy and Fiction vol. 87 issue $4 / 5$, p. 178 .)

(2) Standing in my red sweater and vintage suede skirt, my boots solidly on the floor, I felt almost tall." (Marisa de los Santos, Love walked in: a novel, New York: Dutton).
} 
40. The rooms were clean and almost big.

Its felicity significantly improves over that of (37), partly because it is easier to hear (40) in an imagined context in which the speaker relates an episode involving his or her perception of the relevant rooms. Indeed, sentences such as (40) can be easily found in hotel reviews. ${ }^{11}$

Toledo and Sassoon (2011) defend the idea that relative adjectives are correlated with stable properties while absolute adjectives are correlated with episodic properties. This appears to be a promising suggestion to account for the variable felicity of 'almost beautiful'. As previously pointed out, one of the reasons why (38) sounds natural is that it describes a particular episode, and invites the reader (or hearer) to imagine the cemetery on a specific occasion. Part of the imagery that gets conveyed by (38) is that the appearance of the cemetery on that occasion came close to being described as 'beautiful'. On the other hand, when 'beautiful' is used to attribute a stable property to an individual, its felicity with 'almost' is significantly degraded. Consider:

\section{1. ?? Montparnasse cemetery is grid-shaped, quiet and almost beautiful.}

To bring the point home, suppose that 'beautiful' and 'ugly' are relative adjectives, but such that, like 'dark' and 'bright' (and unlike 'long' and 'big') they can easily shift to an absolute interpretation. That would predict that we should not expect them to align either with 'long' or with 'straight' or 'spotted'. Similarly, suppose that 'elegant' is an absolute adjective, but one that closely resembles relative adjectives in that the minimum standard of application is not determined by the nature of the object to which it is applied. This is, in fact, view defended in Phelan (ms.), who argues that 'elegant' and most aesthetic adjectives, including 'poetic', 'sublime' and 'tragic' are absolute adjectives whose minimum standard of application varies interpersonally. Then again, it would exhibit a behavior that fails to align either with 'long' or with 'spotted'.

Now, Liao and Meskin might welcome this proposal, for they might say that if aesthetic adjectives (like many other adjectives, one could add) can easily shift between relative and absolute interpretations, then this only reinforces their claim that

\footnotetext{
${ }^{11}$ Here are several hotel reviews on TripAdvisor that feature the phrase 'almost big' (although it could not be verified that they were actually written by native speakers of English):

(1) "Rooms are almost big and clean" (https://www.tripadvisor.co.za/ShowUserReviews-g293974d605522-r222749033-Abella Hotel-Istanbul.html)

(2) "The room is almost big and has good stuff like Nespresso machine". (https://www.tripadvisor.ie/ShowUserReviews-g186605-d214540-r426023192Herbert_Park_Hotel-Dublin_County_Dublin.html)

(3) "The apartment is almost big with dining room, bedroom, bathroom. It is very clean and fully refurbished." (https://www.tripadvisor.es/ShowUserReviews-g1021473-d4139232-r359664594Apartments_Bozic-Dreznik_Grad_Karlovac_County_Central_Croatia.html)
} 
these adjectives present an empirical challenge to the relative-absolute distinction. ${ }^{12}$ It is unfortunately beyond the scope of the present chapter to show that the distinction still stands solid in face of these adjectives' presumed shiftiness in meaning. Suffice it to note that the phenomenon of meaning shift is much more general and affects all sorts of linguistic classifications. For one, the literature on verb aspect abounds with examples of verbs that fall into one category, but allow for uses characteristic of a different category. For example, the verb 'build' is normally classified among achievement-denoting verbs, which are infelicitous with modifiers such as "for seven years", as witnessed by (42). And yet, in a suitable context or construction, 'build' with align with activity-denoting verbs, as witnessed by (43) (see Pustejovsky (1991); see also Filip (2002) for literature overview):

42. \#Sally's construction company built this house for seven years.

43. Sally's construction company built houses for seven years.

To bring the point home, the mere fact that an adjective can sometimes behave as absolute and sometimes as relative does not in itself invalidate the relative-absolute distinction, assuming that it makes sense to look for an explanation of this fact (as Toledo and Sassoon (2011), for instance, do) .

\subsection{Presupposition accommodation out of context}

My second set of concerns comes from the fact that the experimental paradigm used in Liao and Meskin (2017) creates an artificial setting, which may partly explain the results. Let us go back to Syrett's original paradigm. Recall that on a standard semantic approach, the way in which a definite description "the F" works is that it is presupposed that there exists one and only one $x$ which has $\mathrm{F}$, and, assuming that both presuppositions are satisfied, the definite description denotes $x$. In ordinary language, we often use definite descriptions even when those presuppositions are not in place. For instance, a colleague of yours might tell you:

44. The daughter of our Department Chair is a mathematician.

You may not have known that the Department Chair had any offspring, hence the daughter's existence and uniqueness cannot be presupposed, and yet, the use of the definite description is felicitous. This is because you, as a hearer of (44), can easily accommodate this presupposition, that is, assume (for the purpose of conversation) that there is one and only one individual who is a daughter of your Department Chair.

With this in mind, let us look at what happens in Syrett's original experiments. Presented with two lines neither of which is straight, the participants are unwilling to

${ }^{12}$ Indeed, Sam Liao (p.c.) commented along these lines on an earlier draft of this chapter. 
accommodate the presupposition that there is one and only one straight line (for neither is straight); similarly, if both disks are spotted, the participants are unwilling to accommodate the presupposition that there is one and only one spotted disk (for both are spotted). But presented with two blocks of significantly different lengths, the participants find it easy to accommodate the relevant presupposition. This is because the threshold of what counts as "long" varies from one context to another (recall that a $20 \mathrm{~km}$ long road is short for a long-distance road in China, but long for a road on which to go on foot). In other words, the presupposition that there is one and only one long block can be made true by placing the threshold in between the two lengths. Interestingly, however, as Kennedy (2011) shows, even with the relative adjective 'long', the participants are not always willing to accommodate the presupposition. Thus if the difference between the two blocks' lengths is not very significant, the participants refuse to pick out the longer block as "the long one" (although they will pick it out if they are instructed to pick out "the longer one"). In other words, people are generally unwilling to place the discriminating threshold for 'long' in between lengths that are close to each other.

Going back to Liao and Meskin (2017), there are at least two reasons why many participants may find it problematic to accommodate the presuppositions that, for each pair of stimuli, there is one and only one that is beautiful, ugly or elegant:

4.2.1. Not sufficiently different. Even if a participant might recognize one object as "more beautiful" (or "uglier" or "more elegant") than the other, this may not be sufficient to tease apart the two objects in such a way as to place the discriminating threshold in between them, so that one of the two comes out as beautiful (ugly, elegant) and the other not. Just as when presented with two blocks whose lengths are not that different, the participants are unwilling to accommodate the presupposition that one and only one of them is long, the same is likely to happen with any two objects that, in the participant's eyes, are aesthetically not that different.

In all fairness, Liao and Meskin are aware of this possibility, to which they refer under the name "no crisp judgments" and which they aimed to address in Study 4. Here is what they write (2017: 388$)$ :

To operationalize the no crisp judgments hypothesis, we examined the mean of difference in the comparative phase, with respect to the participants who refused in the selection phase. For those participants, the mean differences were: Mdiff $=10.50$ for 'beautiful' / Hepworth, Mdiff = 14.55 for 'beautiful' / Moore, Mdiff = 12.33 for 'elegant' / Brancusi, and Mdiff $=9.63$ for 'elegant' / Noguchi. These are not huge differences, but they are not negligible on a 100-point scale either. Although we cannot definitively disprove the no crisp judgments hypothesis, owing to the fact that what counts as a relatively small difference is vague or highly theory dependent, we think the mean differences observed in this study make this hypothesis less plausible.

Contrary to what they claim, I would like to submit that the mean differences observed more likely speak in favor rather than again the hypothesis. For a participant 
to accommodate the existance and the uniqueness presuppositions, the two objects should sit at the scale far enough from each other so that a threshold distinguishing beautiful from non-beautiful (ugly from non-ugly, elegant from non-elegant) can be plausibly placed in between the two. When two objects are placed on a 100-point scale at a less than 15 point interval (and often only 10 point intervals), and when there are no other objects to compare them to, then chances are that they will be perceived close enough to one another so as stick together when assessed for having the property at stake.

4.2.2. Not discriminatory. In ordinary language, when a speaker uses a definite description to communicate with their audience, they normally look for a description that will best do the job of singling out the thing to which they want to refer with the definite description. Suppose that I want to tell you something about one of the two men we see at distance. I could tell you "the man on the left", or "the man holding a glass in his hand" (assuming the other man is not holding a glass) - both of those descriptions will work fine, because they provide easy and salient ways to distinguish the two men. I could tell you "the man who earned his degree first" or "the one who lives in a bigger apartment", but this would be extremely uncooperative, because, even though both descriptions are such that one and only one of the two men satisfies them, those are not descriptions that are particularly helpful, in the imagined context, in getting you to figure out which of those two men I am talking about.

Going back to the studies in Liao and Meskin (2017), one reason that may make it more difficult for the participants to accommodate the presupposition that there is one and only one object that is beautiful, ugly or elegant, is that with respect to the stimuli used in their studies, those properties are not the most discriminatory ones. This is striking in Study 2 with the car and flower stimuli. Presented with two photographs of the same car that appears new on the one and old on the other, the most immediate choice of description for the latter would be "the old one", rather than "the ugly one"; similarly, if I wanted you to pick out the flower that looks faded, I would be more cooperative if I used the description "the faded one" rather than "the ugly one". Given that there are discriminatory properties that, in the context at stake, are more salient than aesthetic properties, this could affect some participants' readiness to comply with the task.

A version of this problem also arises for Study 4, where the sculptures are compared for elegance. In the stimuli used, neither of the sculptures is clearly such that it displays the features associated with the concept of elegance to a higher degree than the other. Although Liao and Meskin insist on 'elegant' being a thick term with a descriptive component, it is far from clear that this descriptive component is playing any role in the participants' understanding of the term, as used in relation to those sculptures. In order to see how the thickness of 'elegant' might affect the pattern of response, it would be desirable to use stimuli which display features conventionally viewed as constitutive of elegance, and which do so to clearly different degrees. 


\section{Acknowledgments}

I would like to thank Florian Cova and Sébastien Réhault for the invitation to contribute to this volume. I am very grateful to an anonymous referee and to Sam Liao for comments on an earlier draft, as well as to the audiences at the Linguae Seminar in Paris, the Foundations and Methods in Natural Language Semantics group in Barcelona, the School of Analytic Philosophy in Tehran, and the Linguistics Department at the Federal University of Santa Catarina in Florianópolis. I also acknowledge support from projects ANR-10-LABX-0087 IEC, ANR-10-IDEX-000102 PSL, and the Spanish Ministry of Economy and Competitiveness, EXCELENCIA programme, project no. FFI2016-80636-P.

\section{References}

Bierwisch, Manfred (1989) "The semantics of gradation" In Manfred Bierwisch and Ewald Lang (eds.), Dimensional Adjectives. Berlin: Springer-Verlag, 71-261.

Burnett, Heather (2016) Gradability in Natual Language. Oxford University Press.

Bylinina, Lisa (2014) The Grammar of Standards: Judge-Dependence, PurposeRelativity, and Comparison Classes in Degree Constructions. LOT Dissertation Series 347. Utrecht: LOT.

Fara, Delia Graff (2000). "Shifting sands: An interest relative theory of vagueness." Philosophical Topics 28 (1): 45-81.

Filip, Hana (2012) "Lexical Aspect”, in Binnick, R. I. (ed.) The Oxford Handbook of Tense and Aspect. Oxford: Oxford University Press.

Glanzberg, Michael (2007) “Context, Content and Relativism”, Philosophical Studies 136:1-29.

Kamp, Hans (1975) Two theories about adjectives. In Edward L. Keenan (ed.) Formal Semantics of Natural Language Cambridge University Press, Cambridge, England, 1975. 123-155.

Kennedy, Christopher (2011) Vagueness and Comparison. In Vagueness and Language Use, edited by Paul Egre and Nathan Klinedinst. Palgrave Studies in Pragmatics, Language and Cognition. Palgrave MacMillan.

Kennedy, Christopher and Louise McNally (2005) "Scale structure, degree modification and the semantics of gradable predicates", Language 81:345-381.

Klein, Ewan (1980) "A semantics for positive and comparative adjectives", Linguistics and Philosophy 4:1-45. 
Liao, Shen-yi and Aaron Meskin (2017) "Aesthetic Adjectives: Experimental Semantics and Context-Sensitivity", Philosophy and Phenomenological Research 94 (2): 371-398.

Liao, Shen-yi, Louise McNally and Aaron Meskin (2016) "Aesthetic Adjectives Lack Uniform Behavior", Inquiry 59: 618-631.

McNally, Louise and Isidora Stojanovic (2017) “Aesthetic Adjectives”, in Young, J. (ed.) The Semantics of Aesthetic Judgment. Oxford: OUP. 17-37.

Morzycki, Marcin (2015) Modification, Cambridge University Press

Phelan, Mark (ms.) "Gradability and Multidimensionality in Aesthetic Adjectives". https://www.academia.edu/34465457/Gradability_and_Multidimensionality_in_ Aesthetic_Adjectives

Pustejovsky, James (1991) The syntax of event structure. Cognition 41: 47-81.

Rotstein, Carmen \& Yoad Winter (2004) Total adjectives vs. partial adjectives: Scale structure and higher-order modifiers. Natural Language Semantics 12(3). 259288.

Sassoon, Galit W. (2013) "A typology of multidimensional adjectives" Journal of Semantics 30: 335-380.

Sibley, Frank (1959) “Aesthetic concepts” Philosophical Review 68:421-450.

Solt, Stephanie (2016) "Ordering subjectivity and the absolute/relative distinction", Proceedings of Sinn und Bedeutung 20

Stephenson, Tamina (2007) "Judge-Dependence, Epistemic Modals, and Predicates of Personal Taste", Linguistics and Philosophy 30: 487-525.

Stojanovic Isidora (2016) "Expressing Aesthetic Judgments in Context". Inquiry 59: 663-685.

Syrett, Kristen (2007). Learning about the structure of scales: Adverbial modification and the acquisition of the semantics of gradable adjectives. Doctoral dissertation. Northwestern University, Department of Linguistics.

Syrett, Kristen, Christopher Kennedy, and Jeffrey Lids (2010). Meaning and Context in Children's Understanding of Gradable Adjectives. Journal of Semantics 27 (1): 1-35.

Toledo, Assaf and Galit Sassoon (2011) “Absolute vs. Relative Adjectives - Variance Within vs. Between Individuals”, Proceedings of SALT 21: 135-154

Yoon, Youngeun (1996) "Total and Partial Predicates and the Weak and Strong Interpretations", Natural Language Semantics 4: 217-236 